GU J Sci, Part C, 5(4): 109-119 (2017)

Gazi Üniversitesi
Fen Bilimleri Dergisi
PART C: TASARIM VE TEKNOLOJI
dergipark.gov.tr/http-gujsc-gazi-edu-tr

\title{
Otomotiv Endüstrisinde Kullanılan Çelik Saclardaki Alaşım Elementlerinin Şekillendirmeye Etkisinin Araştırılması
}

\author{
A. Onur ÖZDEMIR ${ }^{1, *}$, Hikmet ŞİRIN ${ }^{2}$, Çetin KARATAŞ ${ }^{3}$ \\ ${ }^{\text {I} G a z i ~ U ̈ n i v e r s i t e s i, ~ T e k n o l o j i ~ F a k u ̈ l t e s i, ~ O t o m o t i v ~ M u ̈ h e n d i s l i g ̆ i ~ B o ̈ l u ̈ m u ̈, ~ 06500, ~ Y e n i m a h a l l e / A N K A R A ~}$ \\ ${ }^{2}$ Gazi Üniversitesi, Teknoloji Fakültesi, İmalat Mühendisliği Bölümü, 06500, Yenimahalle/ANKARA \\ ${ }^{3}$ Gazi Üniversitesi, Teknoloji Fakültesi, Imalat Mühendisliği Bölümü, 06500, Yenimahalle/ANKARA
}

\begin{abstract}
Öz
Makale Bilgisi

Başvuru: 19/06/2017

Düzeltme: $14 / 11 / 2017$

Kabul: 22/11/2017

$\mathrm{Bu}$ çalışmada, sonlu elemanlar yöntemi kullanılarak analizler yapılmış ve otomotiv endüstrisinde kullanılan altı farklı malzemenin şekillendirilebilirlikleri incelenmiştir. Belirli bir geometride ve başlangıçta $1,5 \mathrm{~mm}$ kalınlığında olan malzemeler için sanal ortamda derin çekme işlemi uygulanarak malzemelerin şekillendirme sınır diyagramları elde edilmiştir. Her bir malzeme için ayrı ayrı elde edilen diyagramlar üzerinden şekillendirilebilirlikler karşılaştırılmış ve deformasyon zorlukları değerlendirilmiştir. Analiz sonuçları doğrultusunda Niyobyum, Titanyum ve Vanadyum elementlerinin malzemelerin șekillendirilebilirliğini negatif yönde etkilediği, Alüminyum elementinin ise şekillendirmeye olumlu etkisi olduğu tespit edilmiştir.
\end{abstract}

\section{Anahtar Kelimeler}

Şekillendirme sinır

diyagramı

Derin çekme sayısal

analizi,

Çelik saclarda

deformasyon hatalart,

Mikro alaşım elementleri.

Keywords

Forming limit diagram, Deep drawing numerical analysis, Deformation failures in steel sheets.

\section{Investigation Of The Effect Of Alloy Elements In Steel Sheets Used In The Automotive Industry}

\begin{abstract}
In this study, analyses were made using the finite element method and the formability were examined of six different materials used in the automotive industry. Deep drawing simulation was made of materials with a specific geometry and initial thickness of $1.5 \mathrm{~mm}$ and forming limit diagrams were obtained. The formabilities were compared over the diagrams plotted separately for each material and the deformation difficulties were evaluated. According to the analysis results, it was determined Niobium, Titanium and Vanadium elements had negative effects and Aluminum element had a positive effect on formability.
\end{abstract}

\section{GIRIŞ (INTRODUCTION)}

Farklı pazarlarda küresel ölçekte çeşitli ürünler üretmek ve satmak amacıyla Otomotiv endüstrisinde ekonomik bir imalat sistemine ve üretim sürecine ihtiyaç duyulmaktadır. Üretim süreçlerinin iyileştirilmesi konusunda çeşitli araştırmalar yapılmaktadır. Bir taşıt parçasının seri üretimine geçilmeden önce tasarımda gerekli değişikliklerin yapılabilmesi için malzeme özelliklerinin bilinmesi gerekmektedir [1]. Doğru malzemenin seçilmesi, atık malzemenin en az olmasını, en az deneme işlemini ve en kısa zamanda üretim yapabilmeyi sağlamaktadır. Bu bağlamda, malzemelerin etkin olarak kullanabilmesi için şekillendirilebilirlik sınırlarının da belirlenmesi önem arz etmektedir. Başarılı bir şekillendirme işleminin gerçekleşebilmesi için; malzeme özellikleri, kalıp geometrisi, pres işlemi vb. birbirlerine uyum sağlaması gerekmektedir. $\mathrm{Bu}$ uyum, seri üretime geçilmeden önce deneme üretimi aşamasında sağlanması gerektiğinden bilgisayar yardımıyla modelleme ve analizler gerçekleştirilerek zamandan, iş gücünden ve maliyetten tasarruf sağlanabilmektedir.

Sac metal şekillendirme sürecinin pratik uygulaması derin çekme işlemidir. Derin çekerek şekillendirme işlemi büyük çoğunlukla taşıt gövde parçalarının imalatında uygulanmaktadır. Derin çekme işlemi iki 
temel aşamadan oluşmaktadır. Öncelikle sac metali yerinde tutmak için baskı plakalarına bir kuvvet uygulanır. Daha sonra zımba sac metali öngörülen derinliğe ulaşana kadar kalıp boşluğuna doğru itmektedir. Bu işlem sırasında boşluk boyunca kalınlık dağılımı, levha yüzeyindeki gerilmeler ve köşelerindeki yer değiştirmeler gibi davranışlar belirlenmektedir [2].

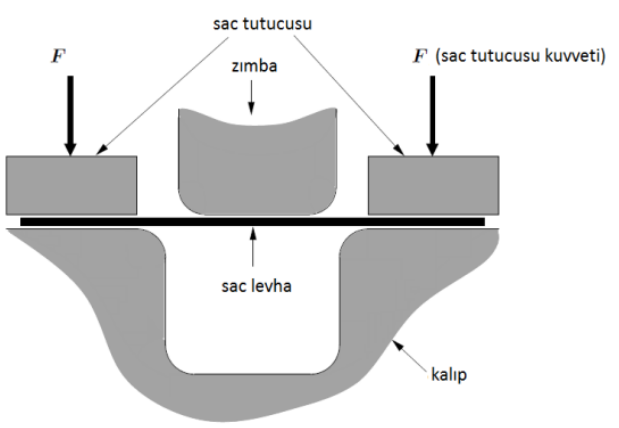

(a)

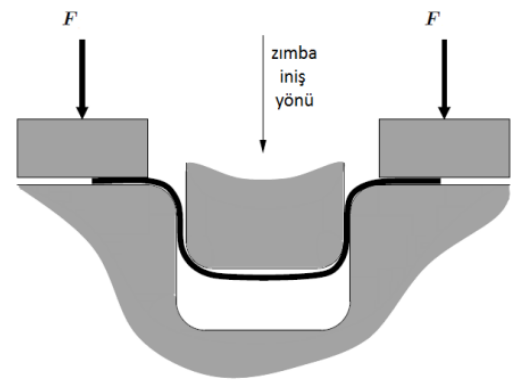

(b)

Şekil 1. Derin çekme işlemi (Deep drawing process)[2]

Malzemenin farklı şekil değiştirme durumlarında şekillendirme sınırlarını büyük ve küçük birim şekil değiştirme (gerinim) oranları cinsinden ifade eden diyagram "Şekillendirme Sınır Diyagramı (ŞSD)" (Forming Limit Diyagram, FLD) olarak adlandırılmaktadır. Şekillendirme sınır diyagramları, şekil verme esnasında ortaya çıkan problemlerin analizi ve çözümlerinde kullanılırlar. Şekil 2'de örnek bir şekillendirme sınır diyagramı görülmektedir. Diyagramın sol tarafı tek eksenli çekmeden, düzlem birim şekil değişimine kadar olan bölgeyi gösterirken, sağ tarafi ise; düzlem birim şekil değişiminden iki eksenli germe halini göstermektedir. Büyük ve küçük birim şekil değiştirme oranlarının pozitif olduğu kısmı; şekillendirme sınır diyagramının sağ tarafı, küçük birim şekil değiştirme oranının negatif olduğu kısmı ise; şekillendirme sınır diyagramının sol tarafidır. Diyagramın üstünde kalan deformasyon değerleri hasarı gösterirken, altta kalan deformasyonlar ise güvenli bölgeyi göstermektedir.

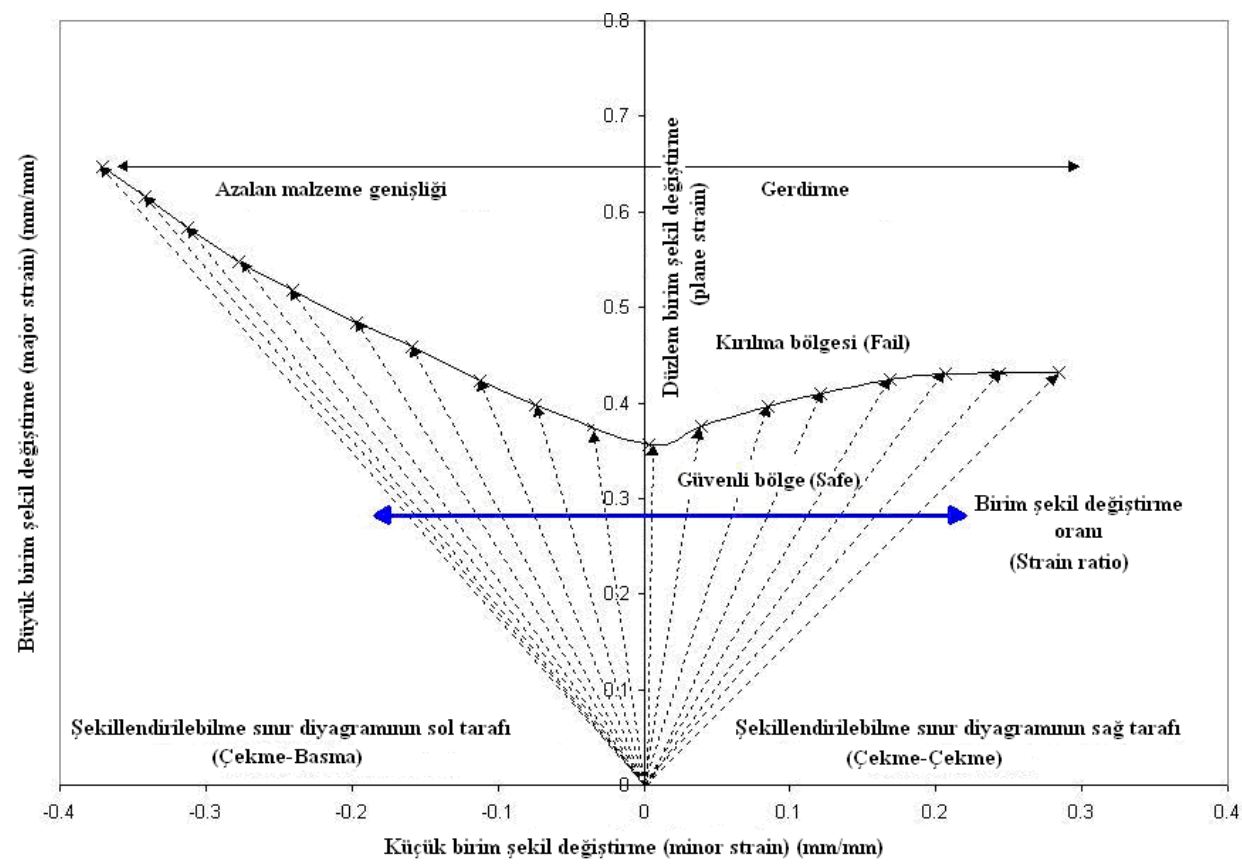

Şekil 2. Şekillendirme sinır diyagramı (Forming limit diagram) [3] 
Malzeme seçimi ve kalıp tasarımı için sac levhaların istenilen geometride şekillendirilmeleri sırasında ne doğrultuda akacağı, yırtılma ve kırışma gibi hataların belirlenmesi gerekmektedir. Sayısal yöntemler kullanılarak malzemenin doğru modellenmesi şekillendirme sürecinin geliştirilmesine katkıda bulunmakta ve kaynak verimliliği sağlamaktadır. Otomotiv endüstrisinde yaygın olarak kullanılan çelik saclar çeşitli özelliklerinin geliştirilebilmesi için bazı mikro alaşım elementleri içerirler. Alüminyum, Titanyum, Niyobyum, Vanadyum gibi ağırlık oranına göre yüksek mukavemete sahip olan alaşım elementlerinin otomotiv saclarında kullanım zorluklarını en aza indirmek için şekillendirme sırasında meydana gelen kırışma, çatlama, geri atma gibi hataların ve bilinmezliklerin tespit edilmesi gerekmektedir.

Akıllı A. yaptığı bir çalışmada, $2 \mathrm{~mm}$ kalınlığındaki Alüminyum alaşımın $25^{\circ} \mathrm{C}$ ve $220^{\circ} \mathrm{C}$ de silindirik kap şeklinde biçimlendirilmesini hem deneysel hem de teorik olarak incelemiştir ve $0^{\circ}, 45^{\circ}$ ve $90^{\circ}$ hadde yönündeki kap kesitlerinden cidar kalınlık değişimleri karşılaştırmıştır. Baskı plakası kuvveti ile sıcaklığa bağlı olarak kalınlıkta homojen incelme ve derinlikte ise artma meydana gelmiştir. Teorik model ile deneysel verilerin \% 90 oranında uyumlu olduğu görülmüştür [4].

Anket O. vd. yaptıkları çalışmada, DC04 sac malzemesi kullanarak hidromekanik derin çekme yöntemini deneysel ve sayısal olarak incelemişlerdir. Deney değişkenleri olarak; farklı sac malzeme çapları, şekil değiştirme hızı, hazne basıncı ve baskı yastığı kuvveti kullanılmıştır. Kırışıklık, yırtılma ve kalınlık değişimi incelenerek şekillendirme sınır diyagramları oluşturulmuştur. Simülasyon programı ile analizler yapılmış ve uzama dağılımları değerlendirilmiştir. Analiz programı ile deney sonuçlarının uyuştuğu görülmüş̧ür [5].

Şener B. yaptığı çalışmada, kalınlıkları ve Karbon oranları aynı olan iki farklı çelik sac malzemenin (IF ERD 7114, ERD 1313) şekil alma kabiliyetleri incelemiş̧ir. Düzlem dış1 test yöntemi kullanılarak şekillendirme sınır diyagramları deneysel olarak elde edilmiş ve yağlayıcı kullanımının etkisi de incelenmiştir. Arayer atomsuz çelik sacın galvanize edilmiş çelik saca göre şekillendirilebilirliğinin daha yüksek olduğu ve mineral yağlayıcının sıvı esaslı yağlayıcıya göre üstün olduğu görülmüştür [6].

Güler H. yaptığı çalışmada, $22 \mathrm{MnB} 5$ ve $30 \mathrm{MnB} 5$ malzemelerine çeşitli ısıl işlemler uygulamış ve mikro yapı değişimlerini incelemiştir. Bor alaşımlı çelik malzemelerin çekme dayanımının sıcak şekillendirme yöntemiyle yaklaşık üç katına çıktığı görülmüştür. Darbe dayanımı, kırılma tokluğu, sertlik ve yorulma deneyleri yapılarak isıl işlem görmemiş malzemeler ile kıyaslama yapılmıştır. Malzemelerin mekanik özellikleri bir sonlu elemanlar programına veri olarak girilmiş ve farklı yükleme ve gerilmelere maruz kalan parçaların sanal analizleri gerçekleştirilmiştir [7].

Çavuşoğlu O. vd. yaptıkları çalışmada, AA6019-T4 ve AA6061-T6 Alüminyum levha malzemelerin mekanik özelliklerinin gerinim hızı ile ilişkili, bu malzemeler üzerine farklı yarı-statik gerinim hızlarında $(0,3 \mathrm{~s}-1,0,03 \mathrm{~s}-1,0,003 \mathrm{~s}-1,0,0003 \mathrm{~s}-1,0,00003 \mathrm{~s}-1)$ tek eksenli çekme testleri uygulayarak incelemiş, şekillendirme sınır diyagramlarını Nakajima testiyle belirlemişlerdir. AA6061-T4 sac malzemesinin AA6019-T4 sac malzemeye kıyasla daha yüksek şekil verilebilirlik özelliğine sahip olduğu rapor edilmiştir. Gerinim hızı arttıkça akma ve çekme mukavemetlerinde hafif bir artış görülmüştür [8].

Yuasa M. vd. yaptıkları çalışmada, Magnezyum-Çinko-(Kalsiyum/Stronsiyum/Baryum) alaşımlarının oda sıcaklığında çekme ve çökertme testleri yapılmış ve soğuk şekillendirme etkilerini incelemişlerdir. 2. grup elementlerin ilavesi akma gerilmesini düşürdügü tespit edilmiştir. Elementlerin atom sayıları azalırken şekillendirme etkinliğinin arttığı belirlenmiştir [9].

Sheng Z. ve Mallick P. yaptıkları çalışmalarında, 6 farklı Alüminyum ile 10 farklı çelik sac malzeme için sac kalınlığının bir fonksiyonu olarak hem deneysel hem de bilgisayar programı yardımıyla şekillendirme sınır eğrileri oluşturulmuş ve malzemeler mikro mekanik durumları dikkate alınarak karşılaştırılmışlardır. Simülasyon sonuçları ile deneysel verilerin uyumlu olduğu tespit edilmiştir. Tek eksenli gerdirme değeri en yüksek 2,5 mm kalınlığındaki düşük Karbonlu S4 çeliğindeyken, $1 \mathrm{~mm}$ kalınlığındaki Al5083-O Alüminyum alaşımında minimum olduğu belirlenmiştir [10].

Till E.T. vd. yaptıkları çalışmada, HCT780XD, HCT780C, HCT690TD ve DX54D geliştirilmiş yüksek mukavemetli çeliklerin (AHSS) çapraz kalıp aleti ile şekillendirme sınır diyagramlarını deneysel olarak çıkartmışlardır. İki farklı çapta zımba kullanılarak etkisi gözlemlenmiş ve zımba çapının büyük olması 
şekillendirilebilirlik seviyesini artırmıştır. Bir simülasyon programıyla şekillendirme sınır eğrileri çizilmiş ve şekillendirme derinliği yaklaşık tahmin edilmiştir. Germe-bükme işlemi söz konusu olduğunda levha kalınlığının artması ve sertleşme derecesinin azalması şekillendirme sınırının iyileştirdiğini göstermiştir [11].

Wiebengaa J.H. vd. yaptıkları çalışmada, DX54D çeliğinin derin çekme deneyleri sonucunda şekillendirme sınır diyagramlarını çıkartmışlardır. Malzemenin çekme testi sonuçları ve mikro yapı özellikleri girdi olarak kullanılarak bir simülasyon modellemesi yapılmıştır. Deney ile program sonuçları karşılaştırıldığında uzama-gerilme değerlerinin benzer olduğu tespit edilmiştir [12].

Machalek Y. ve Cada R. yaptıkları çalışmada, HX220YD çelikten araç B direği imalatı için Autoform yazılımı kullanılarak uygun presle şekillendirme işlemi tasarlamışlardır. Bükme çubukları desteğiyle parça soğuk şekillendirilerek üretilmiştir. 3D CNC yardımıyla parça ölçümleri yapılmış ve simülasyon sonuçlarıyla benzer olduğu belirlenmiştir [13].

Radwanski K., vd. yaptıkları çalışmada, faz bileşenlerinin oranı, morfolojisi ve kimyasal bileşiminin HCT600X çeliğinin mekanik özelliklerine etkisini incelemişlerdir. Termo-mekanik işlemlerle çeliğin mikro yapısında değişiklik yapılmış ve karakterizasyon testleri yapılarak tane çapı, boşluk miktarı, süreklilik gibi malzemelerin özellikleri belirlenmiştir. Ferrit yapıdaki ortalama tane boyutu küçülmesinin gerilme dayanımını artırdığı tespit edilmiştir. Martenzit yapının artmasıyla da sertlik ve çekme dayanımı artmıştır [14].

Abspoel M., vd. yaptıkları çalışmada, yüksek mukavemetli çelik sacların (DX54D, HCT780X) şekillendirme derecesini tayin etmek için iki eksenli ön gerdirme işleminin önemini araştırmışlardır. Nakazima ve Marciniak testlerinin arasındaki farklar karşılaştıılmıştır. Daha önce yapılan çalışmalar da dikkate alınarak tüm malzemelerin yaklaşık \% 4'lük ön gerilmelerinin benzer olduğu ortaya çıkmıştır [15].

Cada R. ve Tiller P. yaptıkları çalışmada, HX220YD, HX220BD, DX54D ve HC220P çelik sacların araç gövdesi B direği için PAM-STAMP programı yardımıyla derin çekilebilirlik ve geri esneme davranışları incelenmiştir. Geri esneme miktarının kalıp tasarımı ve malzeme türünden etkilendiği belirlenmiştir. HX220BD kullanıldığında kalınlık 0,45 - 0,74 mm arasında değiştiği, DX54D kullanıldığında parçanın $\% 25$ 'inde incelme meydana geldiği tespit edilmiştir. Geri esnemenin en az olması için çelik sacin HX220YD malzemeden kullanılmasının uygun olacağı belirlenmiştir. HC220P malzemesinin bu karmaşı parça için uyumsuz bir çelik olduğu görülmüştür. Verilmek istenen şeklin parçaya kazandırılabilmesi için geri esnemenin meydana geleceği bölgenin kalıp geometrisindeki açısının küçültülmesi gerektiği rapor edilmiştir [16].

Bu çalışmada, Autoform analiz programı kullanılarak otomotiv endüstrisinde kullanılan altı farklı çelik sac malzemenin şekillendirilebilirlikleri malzeme içindeki alaşım elementlerine göre incelenmiştir. Malzemeler şekillendirme sınır diyagramları aracılığıyla mukayese edilmiş ve deformasyon hataları değerlendirilmiştir.

\section{MATERYAL VE METOT (MATERIAL AND METHODOLOGY)}

Sac metal levhaların şekillendirilmesinde kullanılan kalıplar yapılmadan önce henüz tasarım aşamasındayken zaman ve maliyet açısından tasarruf etmek için analizleri yapılmaktadır. Bu analizler Autoform, Dynaform vb. programlar aracılığıyla yapılmaktadır. Bu çalışmada ülkemizde yaygın olarak kullanılan Autoform programı kullanılmıştır.

Bu çalışmada kullanılan malzemelerin açıklaması Tablo1'de, malzemelerin mekanik özellikleri Tablo 2'de ve kimyasal bileşimleri Tablo 3'te verilmiştir. 
Tablo 1. Malzemelerin başlıca özellikleri (The main properties of materials) [17]

\begin{tabular}{|c|c|}
\hline Malzeme & Açıklama \\
\hline HX220YD & Çinko ile kaplanarak "galvanize edilmiş” IF çeliği \\
\hline DX54D & Soğuk şekillendirmeye uygun düşük Karbonlu "çinko ile kaplanmış" galvanize çelik \\
\hline DX52D & Soğuk şekillendirmeye uygun düşük Karbonlu "çinko ile kaplanmış" galvanize çelik \\
\hline S500MC & Soğuk şekillendirme işlemlerine uygun orta ve yüksek mukavemetli düşük alaşımlı çelik \\
\hline HCT600X & Yüksek akma dayanımlı ve soğuk şekillendirme işlemine uygun "galvanize edilmiş” çift fazlı çelik \\
\hline HX340LAD & $\begin{array}{r}\text { Soğuk şekillendirme işlemine uygun yüksek mukavemetli, düşük alaşımlı, sürekli sıcak daldırma } \\
\text { yöntemiyle çinko kaplanmış (galvanize) çelik }\end{array}$ \\
\hline
\end{tabular}

Tablo 2. Malzemelerin mekanik özellikleri (Mechanical properties of materials) [17]

\begin{tabular}{|c|c|c|c|c|}
\hline \multicolumn{2}{|c|}{ Malzeme } & \multicolumn{3}{c|}{ Mekanik özellikler } \\
\hline Standart & Kalite & $\begin{array}{c}\text { Çekme dayanımı } \\
\text { (MPa) }\end{array}$ & $\begin{array}{c}\text { Akma dayanımı } \\
\text { (MPa) }\end{array}$ & Uzama \% \\
\hline EN 10923 & HX220YD & $340-420$ & $220-280$ & 32 \\
\hline EN 10346 & DX54D & $260-350$ & $120-220$ & 36 \\
\hline EN 10346 & DX52D & $270-420$ & $140-300$ & 26 \\
\hline EN 10149-2 & S500MC & $550-700$ & 500 & $12-14$ \\
\hline EN 10346 & HCT600X & 590 & $340-440$ & 20 \\
\hline EN 10346 & HX340LAD & $410-510$ & $340-420$ & 21 \\
\hline
\end{tabular}

Tablo 3. Malzemelerin kimyasal bileşim özellikleri (Chemical composition properties of materials) [17]

\begin{tabular}{|c|c|c|c|c|c|c|c|c|c|c|c|}
\hline Malzeme & \multicolumn{9}{|c|}{ Kimyasal bileşim \% } \\
\hline & $\begin{array}{c}\mathbf{C} \\
\text { Karbon }\end{array}$ & $\begin{array}{c}\text { Si } \\
\text { Silisyum }\end{array}$ & $\begin{array}{c}\text { Mn } \\
\text { Manganez }\end{array}$ & $\begin{array}{c}\mathbf{P} \\
\text { Fosfor }\end{array}$ & $\begin{array}{c}\mathbf{S} \\
\text { Kükürt }\end{array}$ & $\begin{array}{c}\mathbf{A l} \\
\text { Alüminyum }\end{array}$ & $\begin{array}{c}\mathbf{T i} \\
\text { Titanyum }\end{array}$ & $\begin{array}{c}\text { Nb } \\
\text { Niyobyum }\end{array}$ & $\begin{array}{c}\text { V } \\
\text { Vanadyum }\end{array}$ & $\begin{array}{c}\mathbf{C u} \\
\text { Bakır }\end{array}$ & $\begin{array}{c}\text { B } \\
\text { Bor }\end{array}$ \\
\hline HX220YD & 0,01 & 0,3 & 0,9 & 0,08 & 0,025 & 0,01 & 0,12 & 0,09 & - & - & - \\
\hline DX54D & 0,12 & 0,5 & 0,6 & 0,1 & 0,045 & - & 0,03 & - & - & - & - \\
\hline DX52D & 0,12 & 0,5 & 0,6 & 0,1 & 0,045 & - & 0,3 & - & - & - & - \\
\hline S500MC & 0,12 & - & 1,7 & 0,025 & 0,015 & - & 0,15 & 0,09 & 0,2 & - & - \\
\hline HCT600X & 0,23 & 2 & 3,3 & 0,09 & 0,015 & 0,01 & - & - & - & 0,2 & 0,006 \\
\hline HX340LAD & 0,12 & 0,5 & 1,4 & 0,03 & 0,025 & 0,015 & 0,15 & 0,1 & - & - & - \\
\hline
\end{tabular}


Analizi yapılan parça geometrisi Şekil 3'te görüldüğü gibi çoklu forma sahiptir. Analiz sonuçları malzeme içerisindeki elementlerin etkisine göre değerlendirilmiştir.

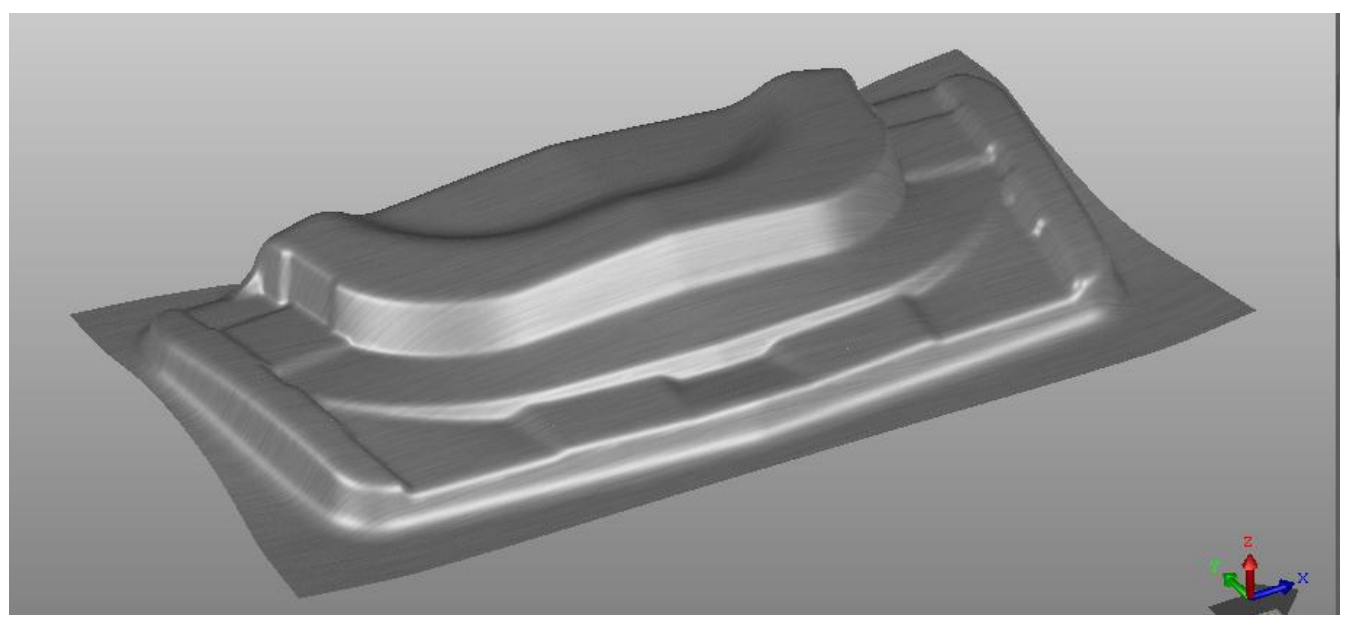

Şekil 3. Analizi yapılan parçanın geometrisi (The geometry of the part being analyzed)

Autoform programı kullanarak derin çekme analizleri sonlu elemanlar yöntemiyle yapılmıştır. HX220YD, DX54D, DX52D，S500MC, HCT600X, HX340LAD malzemeleri seçilerek 1,5 mm kalınlığında ve belirli bir geometride taşıt parçasının derin çekme analizleri gerçekleștirilmiştir. Her malzeme türü için ayrı ayrı şekillendirme sınır diyagramları çizilmiş ve şekillendirme sırasında karşılaşılacak deformasyon hataları belirlenmiştir.

\section{ANALİZ SONUÇLARI VE DEĞERLENDİRME (ANALYSIS RESULTS AND EVALUATION)}

Seçilen 6 farklı malzeme için Autoform programı kullanılarak sayısal analizler gerçekleştirilmiştir. Bunlardan şekillendirilmiş parçanın en olumlu ve en olumsuz olan şekillendirme görüntüleri ve tüm malzemeler için şekillendirme sınır diyagramları verilmiştir.

DX54D malzemesinin üzerinde meydana gelen gerilmeler Şekil 4.a'da ve S500MC malzemesinin üzerinde meydana gelen gerilmeler Şekil 4.b'de görülmektedir.

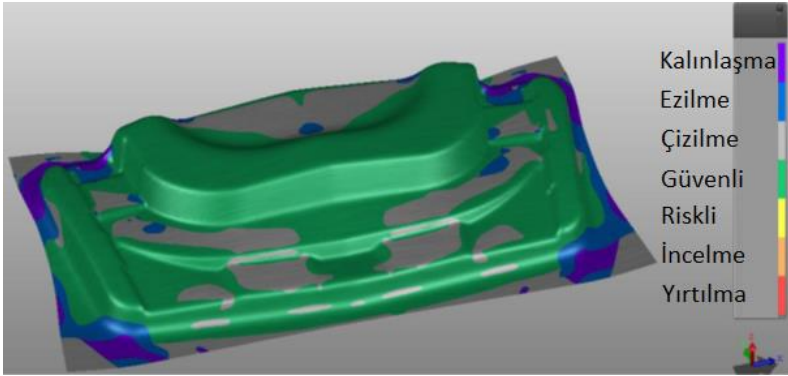

a) $D X 54 D$

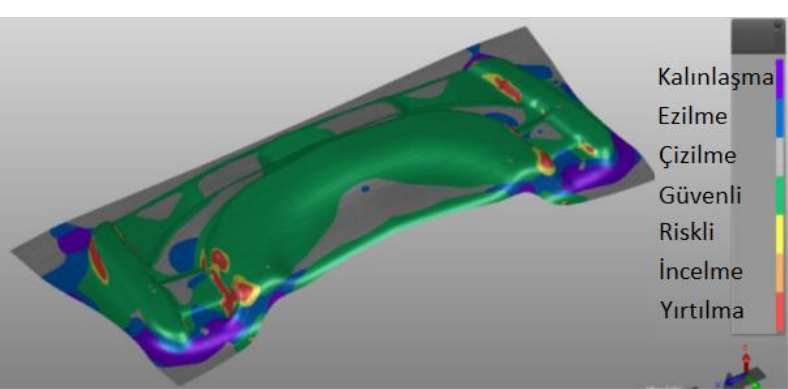

b) $S 500 M C$

Şekil 4. DX54D ve S500MC malzemelerinin şekil verme analizleri (Forming analysis of DX54D and S500MC materials)

DX54D malzemesinin şekillendirme sınır diyagramı Şekil 5.a'da görülmektedir. DX54D malzemesi diyagramda şekillendirme sınır eğrisinin altında kalarak ilgili şekli güvenli olarak alabilmiştir. Parçanın 
hiçbir bölgesinde aşırı incelme olmamıştır. Malzemenin \% 65,65'lik kısmı forma tam uyumlu şekillenirken, malzemede \% 5,74'lük kalınlaşma meydana gelmiş ve maksimum kalınlık 1,67 mm olmuştur. Şekil 5.b'de S500MC malzemesine ait şekillendirme sınır diyagramı görülmektedir. S500MC malzemesi diyagramda şekillendirme sınır eğrisinin üzerine çıktığından parçada yırtılmalar meydana gelmiştir. Şekillendirme sınır eğrisinin üzerinde kalan kusurlar \% 3,41'lik bir alanda kesin yırtılmaların oluştuğunu göstermektedir. Bunun yanı sıra \% 0,35'lik bir alanda da yırtılma riski tespit edilmiştir. Kalınlık dağılımın 0,78 ile 1,68 arasında değişmesiyle birlikte \% 4,18'lik alanda aşırı kalınlaşma görülmüştür.

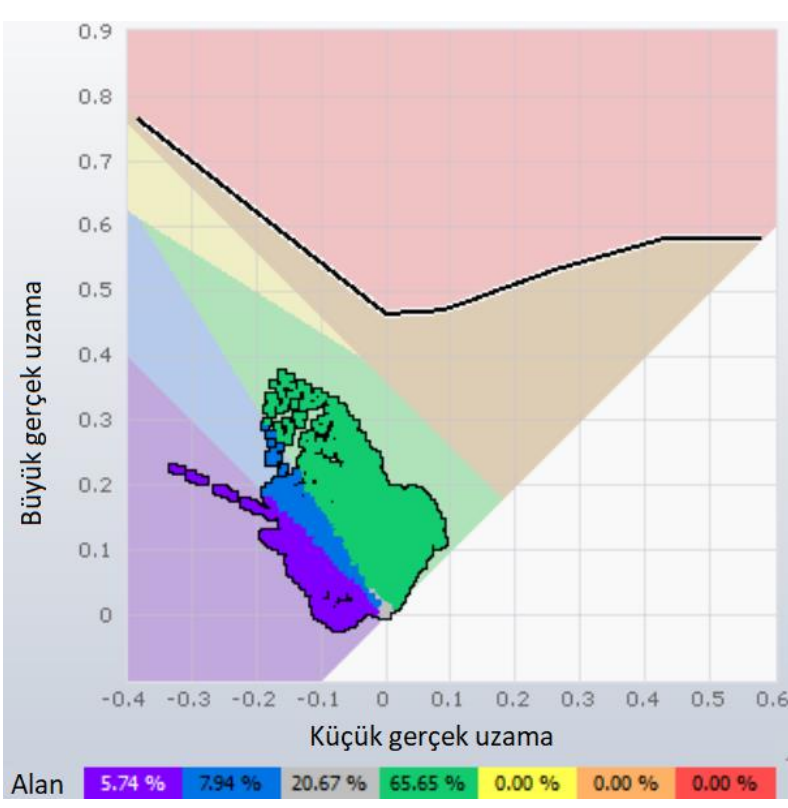

a) $D X 54 D$

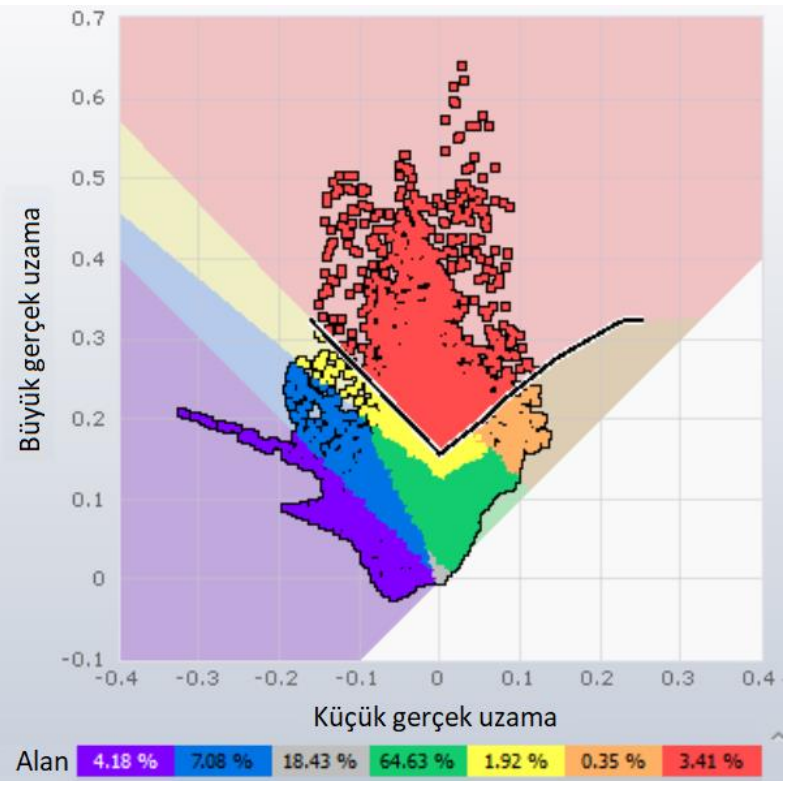

b) $\mathrm{S} 500 \mathrm{MC}$

Şekil 5. DX54D ve S500MC malzemelerinin şekillendirme sinır diyagramlar (Forming limit diagrams of DX54D and S500MC materials)

Şekil 6.a'da HX220YD malzemesi için analiz sonucu elde edilen şekillendirme sınır diyagramı görülmektedir. HX220YD çelik sac şekillendirme sınır eğrisinin altındaki bölgede kaldığından istenilen şekli hatasız olarak alabilmiştir. Malzemenin \% 69,96'lık kısmının kayıpsız şekillendirilebilmiştir. Kalınlık dağılımı 1,12 ile 1,68 mm aralığında olmakla birlikte \% 4,93 kalınlaşma ve \% 0,53 incelme meydana gelmiştir. Şekil 6.b'de DX52D malzemesi için elde edilen şekillendirme sınır diyagramı görülmektedir. DX52D çelik sacında şekillendirme sınır eğrisinin üzerine taşan bölgeler olduğundan parçada kusurlar oluşmuştur. Analiz sonucunda parçanın \% 0,06'lık alanında yırtılma meydana gelmiştir. $\%$ 0,02'lik alanın riskli olduğu ve \% 4,63'lük alanın aşırı kalınlaştığı görülmüştür. Yırtılma dışındaki alanlarda kalınlık 1,03 ila 1,7 mm arasında değişmiştir. 


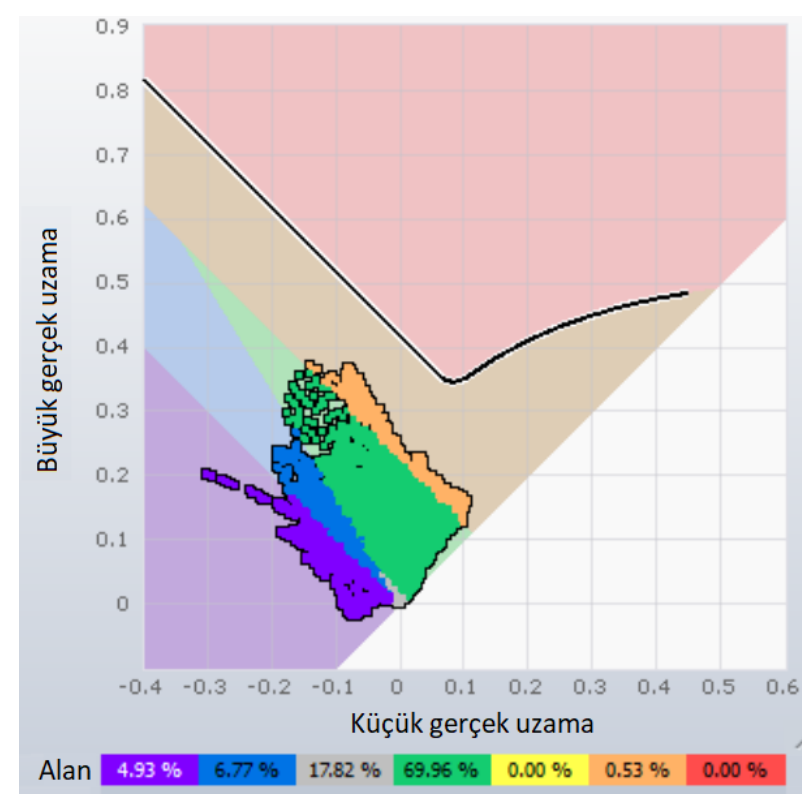

a) $H X 220 Y D$

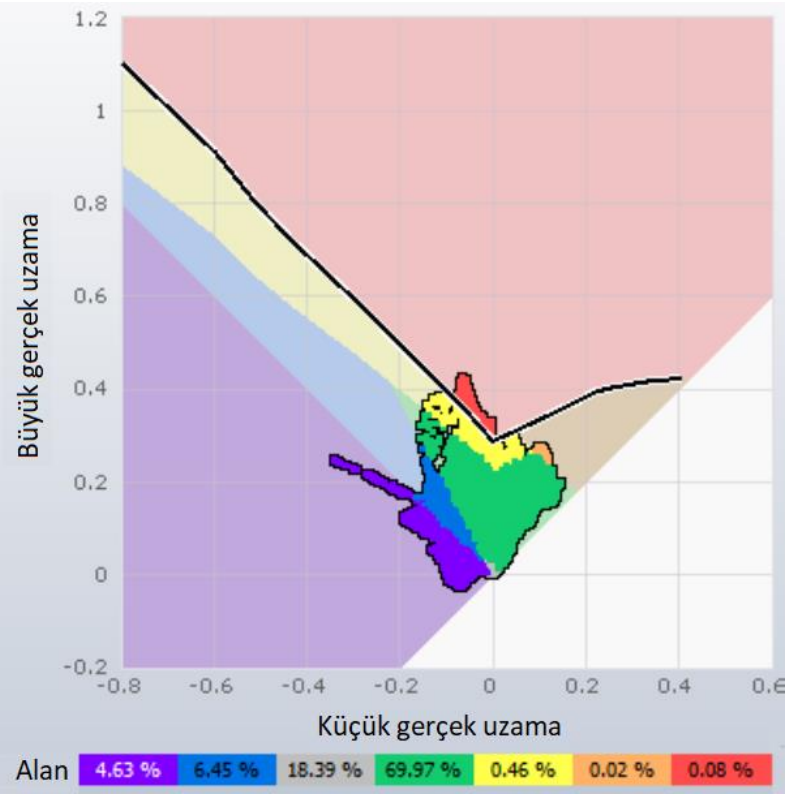

b) $D X 52 D$

Şekil 6. HX220YD ve DX52D malzemelerinin şekillendirme sinır diyagramları (Forming limit diagrams of HX220YD and DX52D materials)

Şekil 7.a'da HCT600X malzemesinin analiziyle elde edilen şekillendirme sınır diyagramı görülmektedir. $\%$ 1,08'lik alanda yırtılma, \% 0,05'lik alanda yırtılma riskinin ve \% 5,67'lik alanda kalınlaşmanın olduğu tespit edilmiştir. Yırtılmaların çoğunlukla düzleme dik yüzeylerde meydana geldiği görülmüştür. Parça kalınlığı 0,99 ila 1,76 mm arasında ölçülmüştür. Şekil 7.b'de HX340LAD malzemesi için şekillendirme sınır diyagramı görülmektedir. Parçanın \% 69,26'lık alanının kusursuz şekillendirilebildiği ve \% 0,56’lık kısmında ise yırtılmanın meydana geldiği görülmüştür. Yırtılan bölgeler dışında kalan alanlarda 1,03 ila 1,69 mm aralığında kalınlık değişimi tespit edilmiştir. HCT600X ve HX340LAD çelik saclar için şekillendirme sınır eğrisinin üzerine taşan bölgeler meydana gelmiştir.

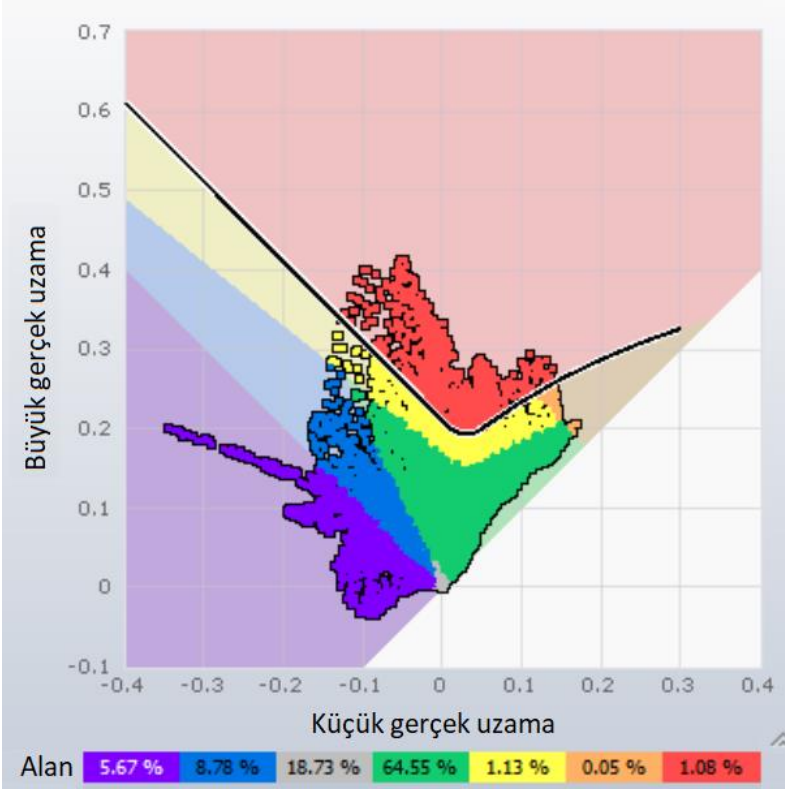

a) $\mathrm{HCT} 600 \mathrm{X}$

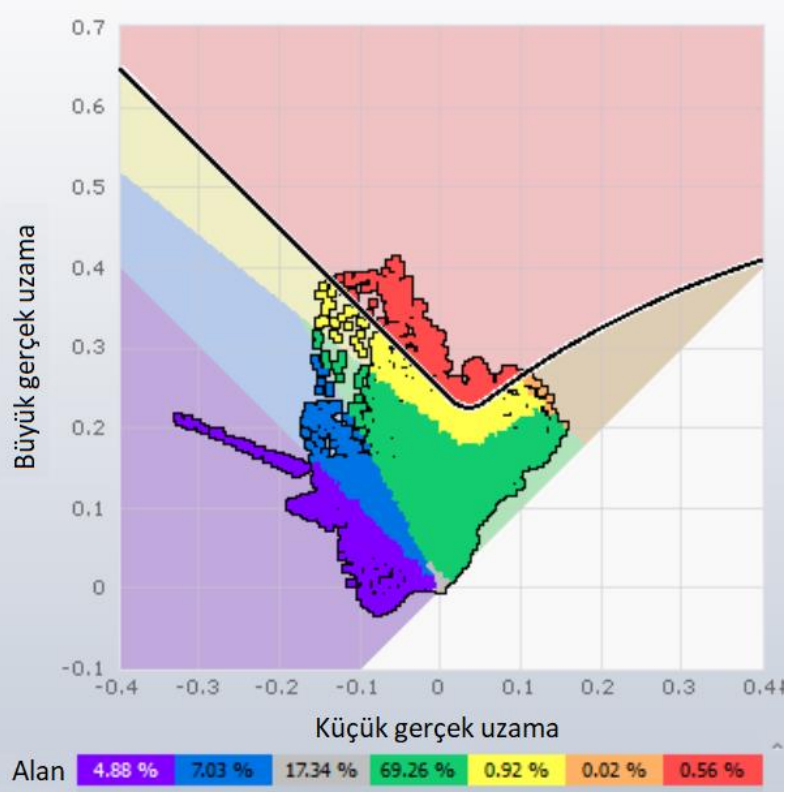

b) $H X 340 L A D$

Şekil 7. HCT600X ve HX340LAD malzemelerinin şekillendirme sınır diyagramlar (Forming limit diagrams of HCT600X and HX340LAD materials) 
Sonlu eleman analizi sonucunda farklı kompozisyona sahip altı farklı malzeme seçeneği için elde edilen veriler Tablo 4'te verilmiştir.

Tablo 4. Analiz sonuçlarının karşılaştırması (Comparison of analysis results)

\begin{tabular}{|c|c|c|c|c|c|c|c|}
\hline \% Alan & Kalınlaşma & Ezilme & Çizilme & Güvenli & Riskli & Așırı İncelme & Yırtılma \\
\hline HX220YD & 4,93 & 6,77 & 17,82 & 69,96 & 0 & 0,53 & 0 \\
\hline DX54D & 5,74 & 7,94 & 20,67 & 65,65 & 0 & 0 & 0 \\
\hline DX52D & 4,63 & 6,45 & 18,39 & 69,97 & 0,46 & 0,02 & 0,08 \\
\hline S500MC & 4,18 & 7,08 & 18,43 & 64,63 & 1,92 & 0,35 & 3,41 \\
\hline HCT600X & 5,67 & 8,78 & 18,73 & 64,55 & 1,13 & 0,05 & 1,08 \\
\hline HX340LAD & 4,88 & 7,03 & 17,34 & 69,26 & 0,92 & 0,02 & 0,56 \\
\hline
\end{tabular}

Yuasa M. vd. yaptıkları çalışmada, sırasıyla Kalsiyum, Stronsiyum ve Baryum alaşım elementlerinin ilavesi Magnezyum-Çinko alaşımlı sac metalin akma dayanımını azaltırken şekillendirilebilirliğine olumlu etkisi olduğunu rapor etmişlerdir [9]. Bu çalışmamızda ise Şekil 8'de görüldüğg̈ gibi Karbon, Manganez, Titanyum, Niyobyum, Vanadyum, Bakır alaşım elementlerinin etkisi ön plana çıkmıştır.

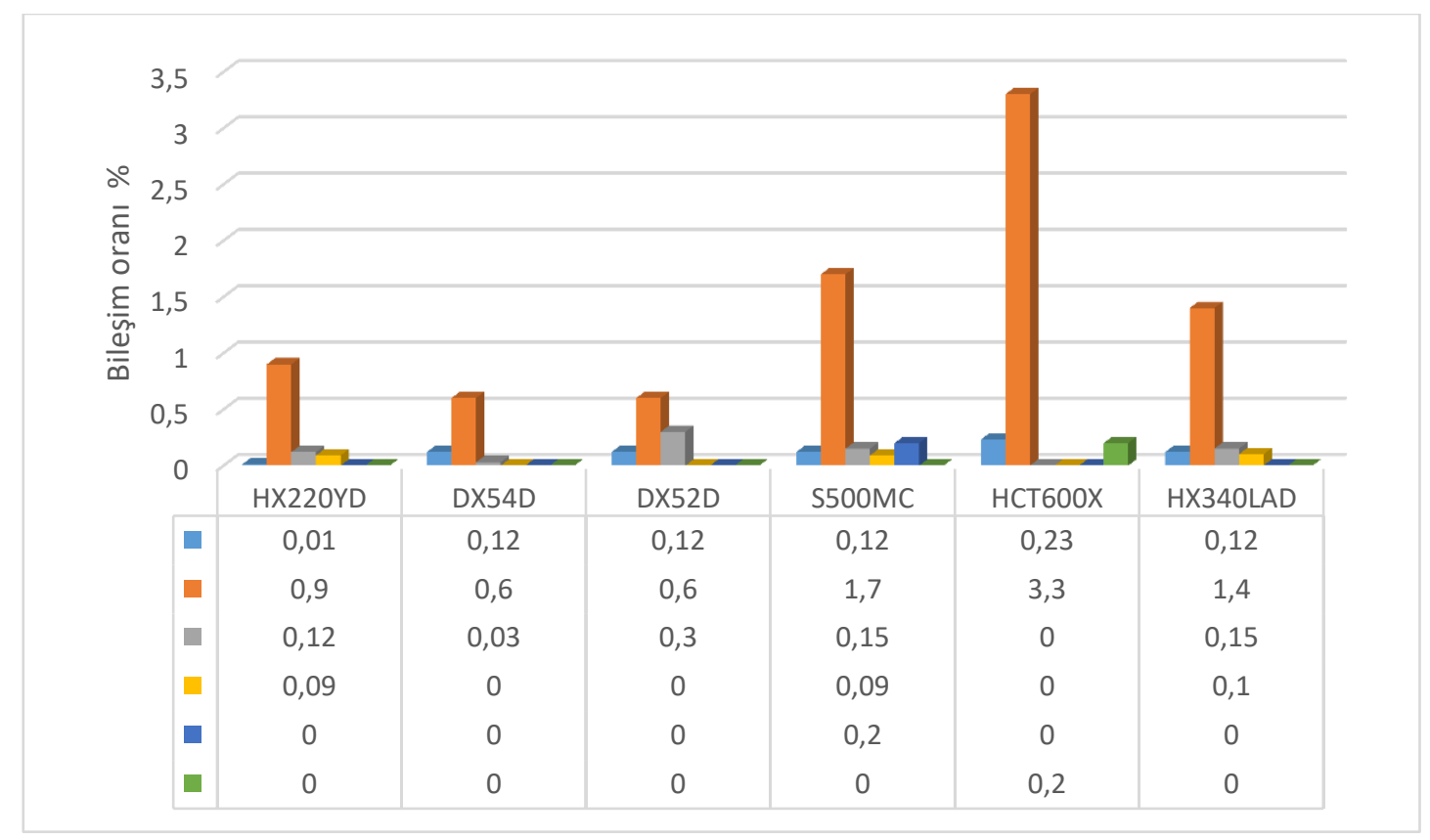

Şekil 8. Analizi yapılan malzemelere ait bazı alaşım elementlerinin bileşim miktarları (Compound quantities of some alloy elements belonging analyzed materials)

DX54D ile DX52D malzemelerinin kimyasal yapılarındaki tek fark Titanyum bileşenidir. DX52D malzemesi 10 kat daha fazla Titanyum içermektedir. Bu da DX52D malzemesinin ezilmenin minimum olduğu ve kalınlığının neredeyse hiç değişmediği alanlar bakımından en güvenli olmasını sağlamıştır. Buna rağmen DX52D malzemesinde ani şekil değişikliğinin olduğu kısmında yırtılma meydana gelmiştir. Analizi yapılan malzemeler içerisinde şekillendirme kabiliyeti açısından parça geometrisine en uygun malzeme olarak DX54D malzemesi belirlenmiştir. DX54D malzemesinde aşırı incelme, yırtılma ve riski hiç olmamakla birlikte en fazla kalınlaşan bölgeye sahiptir. 
Şekillendirme kusuru en az olan malzeme DX54D ile yırtılma ve riski sıfır olan HX220YD malzemesi kıyaslandığında; birim uzama miktarları arasında \% 12,5 ve çekme dayanımlarında ise \% 30 fark olması mekanik özelliklerin şekil alma kabiliyetine etkisini açıkça göstermektedir. HX220YD malzemesinin kimyasal bileşenlerinde Alüminyumun bulunması yırtılma ve riskini azaltmaktadır. Şener B. yaptığı çalışmada, Karbon oranları aynı olan iki farklı çelik sac (IF ERD 7114, ERD 1313) için şekillendirme deneyleri yapılarak arayer atomsuz (IF) çeliğin galvanize çeliğe göre daha kolay şekillendirilebildiğini belirlemiştir [6]. Bu çalışmamızda analizini yaptığımız HX220YD çeliği de düşük Karbonlu bir arayer atomsuz çelik türü olduğundan sonuçlar literatürle benzerdir.

Gerilmelerin akma sınırının çok üzerine çıkması sebebiyle en fazla deformasyon S500MC malzemesinde görülmüştür. Bileşiminde bulunan Manganez sebebiyle mukavemeti artmakta ancak, birim uzama değerini azalmaktadır. Vanadyum ve Niyobyumun tane küçültücü etkisinden dolayı kırılganlı̆̆ı artırmakta ve şekil alma yeteneğini minimuma çekmektedir.

HCT600X malzemesinin kimyasında yer alan yüksek oranda Karbon, Silisyum ve Bakır bileşenleri şekillendirmeye negatif etkisi olmuş ve ezilmeye maruz kalarak parça kalınlığı diğerlerine oranla en az olmuştur. Radwanski K., vd. yaptıkları çalışmada, HCT600X çeliğinin faz ve kimyasal bileşenleri incelenmiş, martenzit yapının oluşumu çekme dayanımını artırdığını, ince taneli yapıya sahip olan malzemelerin iri taneli yapıdaki malzemelere göre daha kolay sertleştiğini, bunun da şekillendirilebilirliği olumsuz yönde etkilediğini tespit etmişlerdir [14]. Bu çalışmamızda yapılan analiz sonucunun da literatür ile uyumlu olduğu görülmüştür.

HX340LAD malzemesinde Alüminyumun varlığı kırılganlığa neden olan Manganezin etkisini dengelemekte ve ortalama bir şekillendirme yeteneği oluşturmaktadır.

\section{SONUÇLAR (CONCLUSIONS)}

Bu çalışmada, Autoform analiz programı kullanılarak HX220YD, DX54D, DX52D, S500MC, HCT600X, HX340LAD çelik sacların şekillendirilebilirlik simülasyonları yapılmış ve içerdikleri alaşım elementlerinin etkileri incelenmiştir. Analiz sonuçları doğrultusunda Niyobyum, Titanyum ve Vanadyumun çeliklerde ortalama tane boyutu küçültücü etkisinden dolayı malzemenin akma-çekme dayanımlarını artırdığı ve şekillendirilebilirliğini negatif yönde etkilediği görülmüştür. Birim uzamanın artışıyla şekil vermenin kolaylaştığı görülmüştür. Alüminyumun akma dayanımını arttırırken, esnekliği artırdığından şekillendirmeye olumlu etkisi olduğu tespit edilmiştir. Karbon, Manganez ve Bakırın çeliğin akma ve çekme dayanımlarını artırırken, sünekliği azalttığından yüzde uzamayı ve şekillendirilebilirliği düşürdüğü, dolayısıyla soğuk çekilebilirliği kötü yönde etkilediği belirlenmiştir.

\section{KAYNAKLAR (REFERENCES)}

[1] Thiruvengadam, H., "Analysis of Part Consolidation Techniques for Automotive BIW Panels based on Advanced Sheet Metal Forming Technologies", Yüksek Lisans Tezi, Clemson Üniversitesi Makina Mühendisliği Bölümü, 2010.

[2] Luet, D.J., "Bounding Volume Hierarchy and Non Uniform Rational B-Splines for Contact Enforcement in Large Deformation Finite Element Analysis of Sheet Metal Forming", Doktora Tezi, Princeton Üniversitesi Makina ve Uzay Mühendisliği Bölümü, 2016.

[3] Uysal E. ve Öztürk F., "Örnek Bir Uygulama ile Yüksek Mukavemetli Çeliklerde Şekillendirme Sınır Diyagramlarının Elde Edilmesi”, 2. Ulusal Tasarım İmalat ve Analiz Kongresi, Balıkesir, 2010. 
[4] Akıllı, A., "AA 5754 Malzemesinin Derin Çekme Metodu ile Soğuk-Sıcak Şekillendirilmesi ve Fem ile Analizi", Yüksek Lisans Tezi, Karabük Üniversitesi Fen Bilimleri Enstitüsü, 2010.

[5] Anket, O., Koruvatan, T. ve Ay, İ., "Sac Malzemelerin Şekillendirilmesinde Şekillendirme Sınır Diyagramlarının Kullanımı”, Politeknik Dergisi, 14 (1), 39-47, 2011.

[6] Şener, B., "Otomotiv Sektöründe Kullanılan Derin Çekme Saclarının Şekillendirilebilirliğinin Analizi”, Yüksek Lisans Tezi, İstanbul Teknik Üniversitesi Fen Bilimleri Enstitüsü, 2012.

[7] Güler, H., "Yüksek Mukavemetli Çelik Sacların Yüksek Sıcaklıktaki Şekillendirme Parametrelerinin İncelenmesi”, Doktora Tezi, Uludağ Üniversitesi Fen Bilimleri Enstitüsü, 2013.

[8] Çavuşoğlu, O., Leacock, A.G. ve Gürün, H., "Forming-Limit Diagrams and Strain-RateDependent Mechanical Properties Of AA6019-T4 and AA6061-T4 Aluminium Sheet Materials", Materials and Technology, 50 (2016) 6, 1005-1010, 2016.

[9] Yuasa, M., Miyazawa, N., Hayashi, M., Mabuchib, M. and Chinoa, Y., "Effects of Group II Elements on The Cold Stretch Formability of Mg-Zn Alloys", Acta Materialia, 83 (2015), 294-303, 2015.

[10] Sheng, Z. and Mallick, P., "Predicting Forming Limit Curve Using a New Ductile Failure Criterion”, SAE Technical Paper, 2017-01-0312, 2017.

[11] Till E.T., Berger E. and Larour P., "On An Exceptional Forming Behaviour Aspect Of AHSS Sheets", International Deep Drawing Research Group IDDRG 2008 International Conference, Olofström/Sweden, 16-18 June 2008.

[12] Wiebengaa, J.H., Atzemab, E.H., Anb, Y.G., Vegterb, H. and Boogaard, A.H., "Effect of Material Scatter on The Plastic Behavior and Stretchability in Sheet Metal Forming", Journal of Materials Processing Technology, 214 (2014), 238-252, 2014.

[13] Machalek, Y. and Cada, R., "Optimization of Flat Forming With The Use of Draw Beads and Finite Elements Method", Transactions of the VSB Technical University of Ostrava, Mechanical Series, 2 (LVII) 1879, 2011.

[14] Radwanski, K., Wrozyna, A. and Kuziak, R., "Role of The Advanced Microstructures Characterization in Modeling of Mechanical Properties of AHSS Steels", Materials Science \& Engineering A, 639(2015), 567-574, 2015.

[15] Abspoel, M., Atzema, E.H., Droog, J.M.M., Khandeparkar, T., Scholting, M.E., Schouten, F.J. and Vegter, H., "Inherent Influence of Strain Path in Nakazima FLC Testing, Tata Steel Research", Development and Technology, IJTC, 2009.

[16] Cada, R. and Tiller, P., "Springback Analysis of Intricate Shape Stamping from Various Materials With The use of Finite Elements Method", Transactions of the VSB Technical University of Ostrava, Mechanical Series, 1 (LVIII) 1891, 2012.

[17] Erdemir Grubu, Ürün Kataloğu, 2015. 